This paper is published in the open archive of Mid Sweden University

DIVA http://miun.diva-portal.org

with permission of the publisher

Citation for the peer-reviewed published paper:

Sikter D, Karlström A, Sandberg C, Engstrand P. Economic perspectives on quality control in TMP refining processes. Nordic Pulp \& Paper Research Journal. 2008;23(3):305-314.

URL to article at publishers site:

http://dx.doi.org/10.3183/NPPRJ-2008-23-03-p305-314 


\title{
Economic perspectives on quality control in TMP refining processes
}

\author{
David Sikter, Holmen Paper, Norrköping, Sweden, Anders Karlström, Chalmers University of Technology, Gothenburg, Sweden, Christer Sandberg, \\ Holmen Paper, Norrköping, Sweden, Per Engstrand, Mid Sweden University, Sundsvall, Sweden
}

KEYWORDS: Refiner control, Economy, Web breaks, Production increase, Quality optimization

SUMMARY: Many studies have been carried out with the goal of improving pulp quality control in TMP refining processes. While it is intuitively clear that minimizing the deviations from the target quality is desirable, the economic value of such reduced quality variations is complicated to estimate. So far not much research has been done in this area related to the pulp and paper industry. This study has been performed to address this issue and to increase the knowledge, in economic terms, of the different mechanisms involved. The focus lies in controlling the pulp quality stability of the refining stage. Several areas in which economic benefits arise from improved quality control are analyzed in more detail. A generic model for estimating the economic value of improved quality optimization is developed. Applied to freeness variability reduction, the model indicates notable economic savings, partly in terms of energy. The connection between pulp quality variations and web-breaks in the paper machine has been studied in a full scale trial. The results indicate that a reduction of web breaks may yield a significant contribution to the profit. Improving the quality control may also enable a production rate increase. In this case there are some energy savings due to improved refiner efficiency at higher throughput. The major economic profit contribution from production increase does however come from the additional volume of paper.

\section{ADDRESSES OF THE AUTHORS: \\ David Sikter (jag@davidsikter.nu) and Christer Sandberg (christer.sandberg@holmenpaper.com): Holmen Paper Development Centre, SE-60188 Norrköping, Sweden. Anders Karlström (anders.karlstrom@CIT.chalmers.se): Chalmers Industriteknik, SE-41288 Gothenburg, Sweden. Per Engstrand (per.engstrand@miun.se): Mid Sweden University, SE-85170 Sundsvall, Sweden. \\ Corresponding author: David Sikter}

In pulp production, quality and production stability are of utmost importance. It is desirable to produce a uniform pulp with the most important properties remaining as constant as possible, but the wood raw material always varies over time and the unit processes, closely connected to each other in complex ways, disturb each other. The production of pulp with stable properties in spite of these variations presents an enormous challenge.

Control and optimization can be performed on different levels. It is only during recent years that millwide control systems have been realized (Deer et al. 2007; Strand, Fralic 2000; Strand et al. 2001). This paper is focused on the control of the refining stage of the TMP process, and not on the mill-wide scale. In many respects the refining stage, and especially the primary refiner, is the most critical stage in the process: it consumes the most energy, and the degree of refining determines the main pulp qualities.

Several studies have been carried out to control refiners with the aim of reducing quality variations (Deer et al. 2007; Ferritsius, Ferritsius 1997; Joensuu et al. 2001; Johansson 2001; Lidén 2003; Sidhu et al. 2005; Sikter et al. 2007; Strand et al. 1993; Strand et al. 2001; Strand et al. 2005). Most studies are focused on one or two quality properties, usually dewatering properties such as measured by the Canadian Standard Freeness (CSF) and fiber characteristics measured by image analysis methods such as Mean Fiber Length (MFL), and attempt to minimize the variations in these. More relevant would probably be to use other quality variables such as strength parameters, degree of fiber treatment, fiber morphology, amount of fines, or some other properties, but results in this direction remain sparse, the most important reason being the lack of necessary sensor technology. To be able to control a parameter, it must be possible to either measure it on-line directly by a sensor or indirectly by a soft sensor based on other measurements, and the speed and accuracy of the measurements must also be adequate for the control purposes.

While it is clear that it is desirable to decrease the quality variations as much as possible, it is complicated to estimate or measure the actual economic value of such improvements (Strand, Fralic 2000). This in turn means that it is difficult to ascertain what resources are profitable to dedicate to this area, to economically motivate the installation of new control systems, and to determine what to focus on (Forsman 2005). According to Rönnbäck (2004), automatic control is often overlooked and given too little resources because the economic potential is not clearly understood and fully appreciated. Rönnbäck relates that surveys show that typically only about $30 \%$ of the control circuits are satisfactory tuned, and estimates that the monetary losses due to suboptimal control are often of the order of millions of dollars in a typical mill. To improve the knowledge and raise the awareness of the economy of automatic control is therefore desirable.

The primary goal of this specific study is to analyze and suggest methods and models for quantification of the savings related to improved refiner quality control. To achieve realistic economic models, specific profitgenerating mechanisms must be identified, and these mechanisms must also be possible to model without making too many or questionable assumptions. Furthermore, the number of parameters in the models should be minimal, and whenever possible the values should be based on empirical measurement. Thus, the methods for establishing the values of the model parameters must also be addressed. 


\section{Methods}

To address the stipulated problem, a literature study was performed and a theoretical analysis was carried out to develop precise economic models. Methods for deriving the values of the model parameters where also analyzed. Values for these model parameters were estimated based on reported values in the literature, when available, and by studying process data from Holmen Paper's Hallsta mill.

In this paper, the models are then applied to a hypothetical newsprint TMP line as an example, to give an indication of what values are involved and their relative importance.

\section{Analysis and Results}

In general, the purpose of a quality control system is to minimize the disturbances in one or more quality parameters. Since the advent of on-line freeness sensors (Bohlin, Hill 1979), quality control in refining has been largely focused on stabilizing this parameter. The reason is that drainage properties are widely recognized as important for the paper machine (PM) and drainage is also often correlated with other important properties such as sheet strength properties and light scattering, but perhaps the most important reason is that mature sensor technology is available for measuring this parameter online. Availability of on-line quality sensors is relatively sparse in most TMP plants (Strand, Fralic 2000).

The process data on pulp quality used in this study will also focus on CSF, not because it is necessarily the best way of characterizing pulp but because it is a de facto standard and one parameter for which on-line sensors are available in the studied mill. However, the models developed here are generic and should be possible to apply with minor changes to any (also potentially better) drainage- or strength-related quality parameter.

For this analysis, it is assumed that a quality parameter $Q$ has been selected (exemplified by CSF). To quantify the disturbances in $Q$, the standard deviation $\sigma_{Q}$ is used. The values before and after a control improvement are denoted by the superscripts ${ }^{\text {old }}$ and ${ }^{\text {new }}$, respectively. We also define $\alpha$ as the controller improvement in relative terms (a list of variables is included as an appendix), i.e.

$$
\alpha \equiv 1-\sigma_{Q}^{\text {new }} / \sigma_{Q}^{\text {old }}
$$

It is reasonable to expect that the positive economic effects will increase with increasing $\alpha$, i.e. controller improvement, and it is arguable that most of the effects can probably be described as roughly proportional to $\alpha$.

The goal of this paper is thus to quantify the economic value of a certain reduction of the disturbances in the parameter $Q$. Table 1 shows a number of results reported in the literature concerning improvements of CSF control.

In this paper, a hypothetical newsprint production line will be used as a numerical example. The PM is assumed to have a production of $P=200000 \mathrm{t}$ /year, the original freeness variation is assumed to be $\sigma_{C S F}^{\text {old }}$ and an improvement of the control by $\alpha=30 \%$ is assumed to be possible.

It should also be pointed out that beside freeness-
Table 1. Some studies of CSF variation reduction achieved by various control strategies.

\begin{tabular}{lcccc}
\hline \multicolumn{1}{c}{ Study } & Mill & \multicolumn{3}{c}{ Results } \\
& & $\sigma_{\text {csF }}^{\text {old }}$ & $\sigma_{\text {csF }}^{\text {new }}$ & $\alpha$ \\
\hline Deer et al. (2007) & Tembec Pine Falls & - & - & $31 \%$ \\
Sikter et al. (2007) & Hallsta & - & - & $28 \%$ \\
Sidhu et al. (2005) & - & - & - & $41 \%$ \\
Strand et al. (2005) & Augusta Newsprint & - & - & $16 \%$ \\
Lidén (2003) & Ortviken & 32.4 & 9.5 & $65-76 \%$ \\
Joensuu et al. (2001) & Hallsta & - & - & $30-50 \%$ \\
Johansson (2001) & - & 11.1 & 3.7 & $67 \%$ \\
Strand et al. (2001) & Abitibi & 34.3 & 24.7 & $28 \%$ \\
Strand et al. (1993) & - & - & - & $50 \%$ \\
\hline
\end{tabular}

control, it is important to manage the fiber length. Fiber cutting must be avoided. Most modern quality control systems therefore also attempt to make sure that the MFL (or some similar measure) does not fall below a certain limit. However, as long as the fiber length is sufficient, the variability in fiber length is usually of less importance than the variability in $\mathrm{CSF}^{1}$. Though frequent fiber cutting may be a major problem in some processes, it is the experience of the authors that the most usual case is that the freeness variability is the main problem, which is why this paper will focus on this type of problems. A prerequisite for the following discussion is thus that fiber cutting is also avoided.

\section{Fast and slow quality variations}

Of course the pulp flow is not a perfect plug flow. The fastest quality variations should thus be evened out by mixing in chests on the way between the refiners and the paper machine. The time dynamics may vary from mill to mill, but variations that occur within a 20 min time frame are probably almost always harmless. It is thus the slower variations, that last longer and are not evened out by mixing, that cause problems.

\section{Measurement speed and accuracy}

The speed and accuracy of the quality sensors are also important factors. The most common type of freeness sensors currently on the market typically have a measurement cycle of about 10 minutes or more ${ }^{2}$, and a measurement accuracy of $\sigma \approx 5$ (Lidén 2003) which is most considerable as typical process variations appear to have $\sigma_{C S F}$ 10-30 ml. Dealing with slow variations, filtering of the signal (thus weighing together several measurements) does improve the accuracy and somewhat reduce this problem, though it is still considerable. In practice, it is probably very difficult if not impossible to achieve a $\sigma_{C S F}$ $<8 \mathrm{ml}$ by feedback control, given the sensor limitations outlined above.

\section{A mill-wide perspective on steam}

As pointed out by among others (Berg, Karlström 2005), it is not enough to consider the energy consumption in the refining stage alone. Instead, a mill-wide energy per-

${ }^{1}$ Too long fibers may result in problem with the formation. However, the fiber length is also usually correlated with freeness.

${ }^{2}$ Recently, a new type of optical sensor has been presented (Johansson et al. 2007) with considerably faster measurement cycles. 
spective must be taken. Most of the electrical energy input to the refiners can be recovered in the form of heat energy in steam. This steam can be used for various purposes within the mill or externally, such as drying in the PM, heating process water and wood chips or district heating, and thus has some economic value. This economic value (on the margin) of recovered, cleaned refiner steam is denoted by $v_{s}[€ / \mathrm{t}]$.

The steam value may vary greatly as there are some mills that have a steam surplus and limited or no possibility to use the excess steam, and there are other mills that have a steam deficiency and need to purchase external fuels to produce the required steam. For mills where there is a steam surplus, the value of the marginal steam may be close to zero. In mills with a steam deficiency the value of the refiner steam would be higher, though not as high as the cost of producing it, since electrical energy is generally a more expensive energy form than heat and there are also considerable energy losses in the process. The value of the steam would also typically show seasonal variations due to climate, and hence $v_{s}$ should be the annual average value.

We denote the cost of electricity by $v_{e}[€ / \mathrm{MWh}]$, and use the factor $\alpha_{\text {rec }}$ to denote the TMP steam recovery efficiency $[\mathrm{t} / \mathrm{MWh}$ ], expressed as the amount of recovered steam per electric energy input to the refiners in question $^{3}$. We then define the factor

$$
\gamma \equiv v_{s} \alpha_{r e c} / v_{e}
$$

This unit-less ratio $\gamma$ should be between 0 and 1 , and denotes the economic value of a tonne of recovered refiner steam divided by the cost of producing it.

If a certain amount of electrical energy $E_{e}$ can be saved every year in the refining stage, the actual effect on the yearly profit, $\Delta V_{E}$, must then be estimated as

$$
\Delta V_{E}=E_{e} v_{e}(1-\gamma)
$$

to take into account the value of the lost recovered steam. The factor $(1-\gamma)$ must not be forgotten as it may have a strong impact on the result. If there is decent recovery efficiency and the recovered steam can be used for valuable purposes a value of $\gamma=0.5$ may be reasonable, and this value will also be assumed for the example mill.

\section{Improved availability through reduction of web breaks}

Web breaks may occur for many reasons, but the major reason is probably insufficient strength (under-refined pulp). In this case, the web breaks would be expected to occur at the weakest spots, and thus it is the large deviations from the desired strength that result in these breaks. Variations in drainage properties may also be a problem for the wire and press section in the PM. It is also quite clear that quality variations generally make the PM more difficult to control.

\footnotetext{
${ }^{3}$ Costs should be on the margin, i.e. constant factors should not be included. That is, the cost of producing additional tonnes in the steam plant and how many additional tonnes of steam are recovered if the refiner power is increased by a certain amount, and so on.
}

Improved control of drainage properties, such as measured by CSF, and thereby indirectly reducing the strength variations, should therefore be expected to reduce the frequency of web breaks somewhat. A major obstacle to quantifying this empirically is that web breaks occur with relatively low frequency, and hence long time periods must be monitored to achieve good statistical certainty. It is also difficult to predict theoretically what reduction in web breaks can be expected from a certain reduction in pulp quality variations. One idea might be to try to estimate $d f_{\text {break }} / d \sigma_{C S F}$, where $f_{\text {break }}$ is the average number of web breaks per day. This was attempted at the studied mill. A long time period covering $1 \frac{1 / 2}{2}$ years was divided into weeks, each week giving a value of $f_{\text {break }}$ and $\sigma_{C S F}$, and a correlation was sought. The analysis did however not give statistically reliable correlations, probably because there were too many other factors involved.

As always, the most reliable results can be achieved if a full-scale test with control improvement is performed. At the studied mill, there has been a recent test installation on one TMP line with a model predictive control (MPC) software from Eurocon Optimation. This system reduced the freeness quality variations after the second stage refiner by $30 \%$ on one of the two refiner lines providing PM2 with pulp. The system was tested for 4 months, and compared to a reference period of $2 \frac{1}{2}$ months. The effect on web breaks in PM2 is shown in Fig 1.

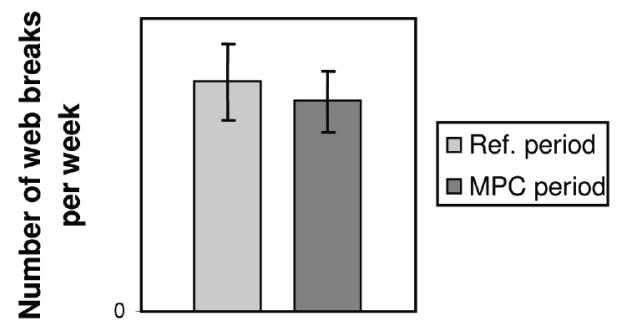

Fig 1. Observed web break frequency with and without freeness control at Hallsta Paper Mill ${ }^{4}$.

The average number of web breaks per week was found to be $8 \%$ lower for the period of improved control. However the statistical uncertainty is high, due to the low frequency of web breaks ( $95 \%$ error bars shown). The odds against the null-hypothesis were computed to be $77 \%{ }^{5}$, so some confidence can be placed in the conclusion that there was indeed a reduction.

The reference period consisted of two separate periods, one before and one after the MPC period. This should reduce the probability of the risk that the observed improvement may be due to a slow trend such as seasonal variations.

A reduction of the web break frequency as a result of installing a new quality control system in a ground wood process has also been reported by Hill (1978). In this case, a reduction by as much as $50 \%$ was recorded.

Given an estimate for $\Delta f_{\text {breaks }}$ and the average monetary loss per web break, $v_{\text {braks }}$, it is easy to compute the added profit due to increased availability as

${ }^{4}$ Scales are unlabeled except for 0 to protect sensitive data

${ }^{5}$ Assuming a normal distributed random value as the null hypothesis. See for instance Miller and Miller (2000) for ways of computing the probability of null-hypotheses. 


$$
\Delta V_{\text {breaks }}=\Delta f_{\text {break }} \cdot 365 \text { days } / \text { year } \cdot v_{\text {break }}
$$

The major economic loss related to a web break is the lost production time. The power and steam consumption of the PM during the startup is another loss, though less important. If only the lost production time is considered, which is clearly a pessimistic way of calculating, then

$$
v_{\text {break }}=\bar{t}_{\text {break }} p_{P M} \cdot c
$$

where $\bar{t}_{\text {break }}$ is the average time a break lasts [h], $p_{P M}$ is the production rate $[\mathrm{t} / \mathrm{h}]$, and $c$ is the contribution margin $[€ / \mathrm{t}]$.

If we use $b \in[0,1]$ to denote the portion of the web breaks that are due to variations in pulp quality, and it is further assumed that the improvement $\Delta f_{\text {break }}$ is roughly proportional to $\alpha$, it would suggest that

$$
\Delta f_{\text {break }} \approx \alpha \cdot f_{\text {break }} \cdot b
$$

Determining the cause of a break is often not easy, but it would seem reasonable to assume that $b \approx 0,3$. This is in line with the result from the trial at Hallsta ${ }^{6}$. For the example mill, it is assumed that $f_{\text {break }}$ is 5 [breaks/day], $\bar{t}_{\text {break }}$ is $15 \mathrm{~min} /$ break, $p_{P M}$ is $27 \mathrm{t} / \mathrm{h}$ (i.e. the original PM availability is $85 \%$ ), and the contribution margin $c$ is 150 $€ / \mathrm{t}$. With these numbers, the addition to the profit becomes $170 \mathrm{k} € /$ year.

\section{Production maximization}

Improved quality control may enable a production increase. In most cases the PM capacity is the production bottle neck (rather than the pulp production capacity), and thus the relation between quality stability and PM productivity must be examined. The economic benefit of increased production is two-fold: firstly, it means more tonnes, and secondly, the refining process is known to be more energy efficient at higher throughput.

Define $k_{p^{+}}$as the factor of production rate increase made possible by a control improvement $\alpha$, i.e.

$$
p^{\text {new }}=p^{\text {old }} \cdot k_{p+}
$$

It is assumed that the same relative production rate increase applies to both the $p_{P M}$ and $p_{\text {ref }}{ }^{7}$. It seams reasonable to assume that

$$
k_{p+}-1 \approx z \cdot \alpha
$$

i.e. that the production increase made possible is roughly proportional to the control improvement, the proportionality factor being designated $z$. The factor $z$ is the most challenging parameter in this model to estimate.

\footnotetext{
${ }^{6}$ Since only one of two lines were controlled, $\alpha$ should be about $15 \%$, and the improvement predicted by the model would be $4.5 \%$, which is not far off the observed $8 \%$ (with large uncertainty). Note also that according to these results $b \approx 0.3$ would be a conservative estimate.

${ }^{7}$ This may not always be the case (consider for instance if there is a pulp shortage), but is probably the most usual situation.
}

There are a number of reasons why improved quality control may enable a production increase. The speed of the PM must be set pessimistically, so that the machine handles most of the pulp with low quality that is produced. By reducing the quality disturbances, it should therefore be possible to increase the PM speed somewhat, though it is difficult to estimate how much. (Strand, Fralic 2000) reported an increase of PM speed by $15 \%$ after installation of a mill-wide control system, but the large number of process control changes that were made in this project would seem to make it impossible to ascertain how much the individual improvements contributed to the total speed improvement, and another point of uncertainty is that the speed used before the control installation may have been set too pessimistically.

Another consideration is that pulp quality probably becomes more difficult to control when the production is increased, due to smaller plate gap and other factors. This effect could also be seen in production data from the investigated mill, by plotting the freeness stability as a function of production rate, see Fig 2.

Freeness stability versus production rate

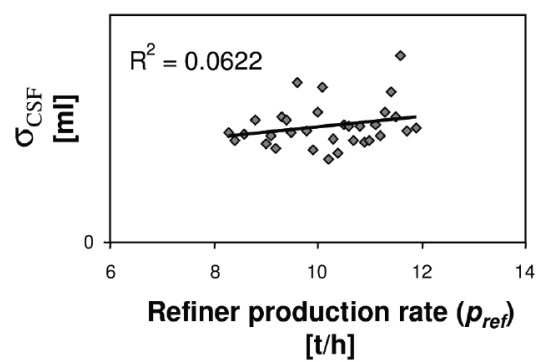

Fig 2. Freeness stability versus production rate at Hallsta Paper Mill. ${ }^{8}$

The scatter in the data is quite large, giving a low $\mathrm{R}^{2}$ value, but according to a T-test the correlation is statistically significant to the 0.995 confidence level. There is thus some support for the hypothesis that quality stability is more difficult to achieve at higher production rates. This constitutes another reason why quality variations may prevent a production rate increase.

First turning to the issue of improving energy efficiency by increased refiner throughput, it is necessary to know the energy efficiency as a function of $k_{p+}$. The specific energy consumption (SEC, in $\mathrm{MWh} / \mathrm{t}$ ) at constant quality and raw material must then be considered as a function of the production rate through the refiner, $p_{\text {ref. }}$. Assuming that this function is approximately linear around the original operating point, defined by $p_{\text {ref }}^{\text {old }}$ and $S E C^{\text {old }}$, it is useful to define the unit-less ratio $\beta$ by

$$
\beta \equiv-\frac{d S E C}{d p_{\text {ref }}} \frac{p_{\text {ref }}^{\text {old }}}{S E C^{\text {old }}} \quad \text { (at constant quality) }
$$

\footnotetext{
${ }^{8}$ The data used in the plot consisted of 6 months of normal production. The time series was divided into 650 segments of 5 hours each, and the average production rate and $\sigma_{C S F}$ were computed for each segment. Then the points were divided into classes based on production rate (in steps of $0.1 \mathrm{t} / \mathrm{h}$ ) and the average value of $\sigma_{C S F}$ for each class is plotted in the graph. To anonymize the data, the $Y$-axis is unmarked except for the origin.
} 
The value of $\beta$ can be obtained from step responses on the specific refiner(s) and is thus relatively simple to measure. Note that the linear relation between energy consumption and production rate obtained from normal production data (Deer et al. 2007) cannot be used to estimate $\beta$, since in such data there would be variations in quality and raw material; step

Table 2. Previous studies on the relationship between energy efficiency and refiner throughput, and the derived values of $\beta$. responses must be performed.

Table 2 compiles the results from a number of reported trials, where roughly equal pulps were produced at different production rates, and the value of $\beta$ derived from these reports. Also, values obtained in the course of this study are included.

The table covers 3 different sources, 6 refiners of various types, a production span from 3.2 to $14.4 \mathrm{t} / \mathrm{h}$, a freeness span from 120 to $300 \mathrm{ml}$, and tensile span from 21 to $41 \mathrm{Nm} / \mathrm{g}$. Yet interestingly, the value of $\beta$ is fairly similar in all cases, except for the CD76" (in this case production was not the only manipulated variable, however the authors noted that the rotational speed did not seem to change the production rate - energy consumption relation). It therefore seems plausible to conjecture that a typical value of $\beta$ is about 0.3 .

From the definition of $\beta$ and assuming approximate linearity it follows that the change in required specific energy $(\triangle S E C)$ when increasing the production rate by a factor $k_{P+}$ and still maintaining quality is given by the expression

$$
\triangle S E C \equiv S E C^{\text {new }}-S E C^{\text {old }}=\frac{d S E C}{d p_{\text {ref }}} \Delta p_{\text {ref }}
$$

Hence the increased profit due to improved energy efficiency, $\Delta V_{p+c}$, is obtained by

$$
\Delta V_{p+e}=-\Delta S E C \cdot P^{n e w} v_{e}(1-\gamma)
$$

Note that the factor $(1-\gamma)$ should be applied, as this mechanism of saving energy results in steam loss. Eq (11) simplifies to

$$
\Delta V_{p+e}=S E C^{\text {old }} P^{\text {old }} v_{e} k_{p^{+}}\left(k_{p^{+}}-1\right) \cdot \beta(1-\gamma)
$$

In other words, the energy savings $\Delta V_{p+c}$ are approximately proportional to $k_{p^{+}}-1$ (as long as $k_{p^{+}} \approx 1$ ), and the proportionality constant can be established quite easily.

The increased profit from the selling of additional tonnes, $\Delta V_{p+c}$, is given by

$$
\Delta V_{p+c}=c \cdot P^{\text {old }}\left(k_{p+}-1\right)
$$

where $c$ is the contribution margin. This expression is also proportional to $k_{p+}-1$.

It remains to establish a plausible value of $z$. The $z$ parameter can be expected to vary significantly depending on what the limiting factors are and how

closely they are connected to quality variations, and detailed understanding of the paper machine is probably needed. In the absence of empirical data, the value of $z=0.05$ is assumed for the example mill. In other words, it is assumed that the $30 \%$ improvement of the quality control will enable a relatively modest production increase of $1.5 \%$. As this is only one tenth of the increase reported by (Strand, Fralic 2000), it would seem that the value of $z$ is pessimistically chosen.

The other parameters of the models are easier to estimate, and the values assumed are $\beta=0.3, v_{e}=40$ $€ / \mathrm{MWh}^{9}, S E C^{\text {old }}=2 \mathrm{MWh} / \mathrm{t}$. With these numbers, the estimated savings in energy would be $37 \mathrm{k} € /$ year, and the contribution from the additional volume would be 450 $\mathrm{k} € /$ year.

One other way of exploiting the energy saving mechanism of increased refiner throughput when there is no need for a total increase in production would be to employ a strategy of shutting down the refiners more often and keeping higher production rates when running. To analyze the value of such strategies would probably be very complicated and mill-specific, and is thus not attempted here, but if such an analysis were to be undertaken, an estimate such as that from $E q$ (11) would be needed in the model.

\section{Reduced out of spec production, quality target shift and optimization}

The most commonly used method of estimating economic value of reduced disturbances in a variable is based on the ability to avoid unacceptable values (Forsman 2005). This assumes that there is a certain, sharp limit which if exceeded leads to some measurable loss, for instance an emergency shutdown or a product which is discarded or downgraded (sold at lower price). However, such well-defined limits are usually hard to identify, and when there are such distinct limits they are usually found in the end of the process, i.e. after the paper machine, where there are quality guarantees of the final product to be met. These limits are difficult to translate into sharp limits on pulp quality. While many mills have defined pulp quality windows, these are usually in reality just guidelines, thus difficult to associate with any loss of value.

To address these problems, a model without hard limits

${ }^{9}$ Electricity prices and steam value may of course vary considerably from mill to mill and over time. 
is proposed here. It assumes that the cost per tonne, $v$, depends on the quality and some other factors, thus, that it can be modeled as a function

$$
v=v_{Q}(Q)+v_{\text {others }}
$$

The function $v_{Q}$ should have a minimum, i.e. an optimum quality $Q_{\text {opt }}$ that is neither too high nor too low. Producing too high quality is a waste of resources, and producing too low quality will also increase costs due to product rejection or runability problems. The average cost per tonne, $\bar{v}$, should be obtained as

$$
\bar{v}=\overline{v_{Q}(Q)}+\bar{v}_{\text {others }}
$$

The term $v_{\text {others }}$ is assumed to be independent of $Q$, and thus the effect on the average cost per tonne, $\Delta \bar{v}$, from a certain change in the distribution of $Q$, should then be given by

$$
\Delta \bar{v}=\Delta\left(\overline{v_{Q}(Q)}\right)
$$

Therefore define

$$
\bar{v}_{Q} \equiv \overline{v_{Q}(Q)}
$$

Assuming that the quality is normally distributed with mean $\bar{Q}$ and standard deviation $\sigma_{Q}$, the value of $\bar{v}_{Q}$ can be computed by the expression

$$
\bar{v}_{Q}=\int_{-\infty}^{\infty} v_{Q}(Q) \cdot N\left(Q, \bar{Q}, \sigma_{Q}\right) d Q
$$

where $N$ is the normal distribution function. Still, an expression for the function $v_{Q}(Q)$ is needed. As a simplifying assumption, it is assumed that the function $v_{Q}(Q)$ can be approximated by two joined linear segments, as illustrated in Fig 3.

This type of approximation is probably viable, at least in a small area around the optimum. It also allows the curve to be asymmetric, i.e. the slopes of $v_{Q}(Q)$ can be different on each side of the minimum. Since the goal is to compute differences in $\bar{v}_{Q}$, the absolute value is not important. Instead it is enough to characterize the approximation by the two respective slopes, $d v_{Q} / d Q$ on each side of the optimum. These slopes can be denoted by $D_{\text {left }}$ and $D_{\text {right }}$. However, it turns out to be practical to use instead the pair $(D, k)$ to characterize the function, defined by

$$
\begin{aligned}
& D \equiv \min \left(\left|D_{\text {left }}\right|,\left|D_{\text {right }}\right|\right) \\
& k \equiv \max \left(\left|D_{\text {left }}\right|,\left|D_{\text {right }}\right|\right) / D
\end{aligned}
$$

In other words, $D$ denotes the absolute value of the flattest of the two slopes and $k \geq 1$ is unit-less and defines the degree of asymmetry of the cost function $(k=1$ for the symmetric case).

Using this approximation, it is possible to proceed. A process is optimized with regards to the quality set point, $\bar{Q}$, if this set point is chosen so that $\bar{v}_{Q}$ is minimized.

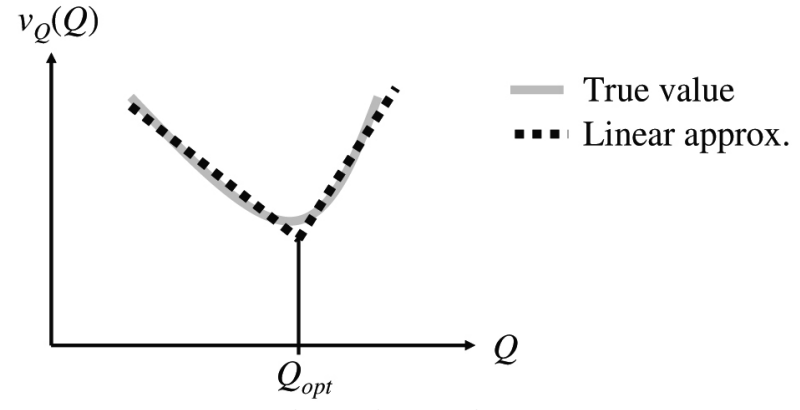

Fig 3. Assumed approximation format of the cost function.

Denote the optimum set point by $\bar{Q}_{o p t}$. It is important to note that $\bar{Q}_{o p t}$ is not the same as $Q_{o p t}$. This may seem counter-intuitive, but consider a strongly asymmetric case, where the costs increase more sharply on one side of $Q_{\text {opt }}$ than on the other. Then avoiding producing quality on the side with the sharp cost increase is more important than avoiding producing quality on the other side.

After some algebra, the assumptions outlined above allow the optimum set point to be obtained by

$$
\bar{Q}_{\text {opt }}=Q_{\text {opt }}( \pm) \sigma_{Q} \Phi^{-1}(k /(k+1))
$$

where $\phi^{-1}$ is the inverse of the cumulative standard normal distribution function and the sign of the $( \pm)$ is determined so that $\bar{Q}_{\text {opt }}$ lies on the side of $Q_{\text {opt }}$ with the flattest slope. Assuming that this optimal set point is used, it follows that

$$
\bar{v}_{Q}=v_{Q}\left(Q_{o p t}\right)+D \sigma_{Q} F(k)
$$

where $F(k)$ is a unit-less function that depends only on the asymmetry factor $k$. The exact mathematical expression for $F$ is

$$
F(k) \equiv(k+1) / \sqrt{2 \pi} \cdot e^{-1 / 2 \Phi^{-1}(k /(k+1))^{2}}
$$

Finally, the average change in cost per tonne resulting from a certain improvement in the quality controller, $\Delta \bar{v}_{Q}$, can be simply expressed as

$$
\Delta \bar{v}_{Q}=D \cdot\left(\sigma_{Q}^{\text {new }}-\sigma_{Q}^{\text {old }}\right) \cdot F(k)
$$

The yearly profit increase due to better optimization, $\Delta V_{Q o p t}$, is then obtained by

$$
\Delta V_{Q o p t}=-\Delta \bar{v}_{Q} \cdot P
$$

The optimal set point shift $\Delta \bar{Q}_{\text {opt }}$ is given by

$$
\Delta \bar{Q}_{\text {opt }}=( \pm)\left(\sigma_{Q}^{\text {new }}-\sigma_{Q}^{\text {old }}\right) \Phi^{-1}(k /(k+1))
$$

where the choice of sign of the $( \pm)$ is such that the set point is moved closer to the optimum $Q_{\text {opt }}$.

The model is simple to apply if estimates of $D$ and $k$ can be made, and these may in many cases be easier to estimate than to identify hard limits. Estimating a precise value of the asymmetry factor $k$ may be difficult, but it turns out that the value of $k$ has relatively minor impact 
on the result since $F(k)$ grows very slowly ${ }^{10}$ with $k$. Even an extremely asymmetric cost function with $k=100$ only increases the result by a factor 3.4 compared to $k=1$. Semantically, this implies that the most important parameter according to this model is the flatter of the two slopes. If a value for the flattest slope can be obtained, a good estimate of the profit should be possible to make.

To apply this model to CSF control, choose $D$ to be the slope $d v_{Q} / d Q$ where too low freeness is produced. This should be the flattest slope since the experience is usually that it is better to over-refine (i.e. to refine to a freeness lower than $Q_{\text {opt }}$ ) than to under-refine pulp. This is also why improvement in freeness control is often motivated by the goal of increasing the freeness set point (Deer et al. 2007).

A value of $k=10$ is assumed here. As this value is of less importance than $D$, the focus should be to obtain an estimate of this parameter. One cost that is clearly a consequence of over-refining pulp is the extra energy needed, energy that is essentially wasted ${ }^{11}$. This cost can be estimated with relatively high certitude from the relationship between freeness and specific energy. This cost derivative, denoted $D_{e}$, is given by

$$
D_{e} \equiv\left|d S E C / d C S F \cdot v_{e}(1-\gamma)\right|
$$

Note that the energy used for the over-refining should result in more recoverable steam, and hence the factor $1-\gamma$ should be applied.

However, the electrical energy consumption in the refiner is not the only cost associated with over-refining pulp. Just like under-refining, over-refining can lead to runnability problems like web breaks. Low freeness pulp, being more difficult to drain, should also increase the steam need in the drying section to reach the right dryness, but estimates in the studied mill indicates that this cost derivative, denoted $D_{s}$ and given by $D_{s}=\left|d S / d C S F \cdot v_{s}\right|$ where $S$ is the specific steam consumption, is negligible in comparison to $D_{e}\left(D_{s}\right.$ being two orders of magnitude smaller than $D_{e}$ ). In each case, assuming $D \approx D_{e}$ is most certainly conservative.

For the example mill it is assumed that the controller operates around the freeness region of $130 \mathrm{ml}$, where a typical value of $d S E C / d C S F \approx-0.0015 \mathrm{MWh}(\text { ton } \cdot \mathrm{ml})^{12}$. The estimated average cost reduction according to the model then becomes $0.24 € / \mathrm{t}$, adding to the profit by $\Delta V_{\text {Qopt }}=48 \mathrm{k} € /$ year. The optimal freeness set point shift, $\Delta C S F_{\text {opt }}$, evaluates to $6 \mathrm{ml}$, i.e. the freeness set point should be increased by $6 \mathrm{ml}$ after the control improvement.

This set point shift results in a reduction of the average specific energy consumption, $\triangle S E C$, according to

\footnotetext{
${ }^{10} F(k)$ can be fairly well approximated by $F(k) \approx 0.21 \ln (k)+0.41$, i.e. it grows approximately logarithmically.

${ }^{11}$ The fact that the tons of pulp which are more heavily refined ought to have some better quality should not make a difference on the selling price. The customer sees the improvement only as a disturbance, which swings both ways.

${ }^{12}$ The value depends on which parameter is used to control the SEC. Here it is assumed that the manipulated variable is the plate gap.
}

$$
\Delta S E C=\frac{d S E C}{d C S F} \Delta \overline{C S F}_{o p t}
$$

And consequently the energy related savings from the increased freeness set point, $\Delta V_{C S F+e}$, can be obtained from

$$
\Delta V_{C S F+e}=-\Delta \overline{S E C}_{o p t} \cdot P \cdot v_{e}(1-\gamma)
$$

which evaluates to $36 \mathrm{k} € /$ year. Note that these savings are already included in $\Delta V_{\text {Qopt }}$. This can be interpreted as $75 \%$ of the savings $\Delta V_{Q o p t}$ in the example being describable as energy savings.

\section{Other sources of economic value}

The mechanisms mentioned so far are not the only positive effects from quality control. According to Rönnbäck (2004), the profitability of improved control commonly cannot be motivated by one single mechanism, but rather the motivation must often be based on the sum of several minor sources of profit. In the context of improved refiner quality control, a number of additional positive effects are worth mentioning:

- Decreased startup times and faster shifts between different product grades should be expected

- A more uniform product should give fewer problems for the customer

- Stabilizing one system often makes it possible to improve the stability in other related systems

- More flexibility in positioning the operating window

It will not be attempted here to quantify such effects, since it probably would be very complicated to model them and difficult to make credible assumptions, but these effects may also be economically important.

\section{Discussion}

Four different mechanisms of economic profit increase resulting from improved freeness/drainability properties control have been discussed and modeled: improved PM availability through reduction of web breaks, enabled production increase with resulting improved energy efficiency and volume increase, and improved quality optimization/target shift. Further, all these savings, as described by the developed models, are proportional to the control improvement $\alpha$ and the original yearly production $P^{\text {old }}$. It is thus possible to define a factor $\kappa$ which is independent of $\alpha$ and $P^{\text {old }}$, according to

$$
\Delta V \equiv \alpha P^{o l d} \cdot \kappa
$$

for each mechanism. The results can thus be compared as in Table 3.

\section{Model sensitivity}

All model parameters except for $b, k$ and $z$ should be known or straightforward to measure in a given mill. The values for $b, k$ and $z$ that have been suggested here seem reasonable given the empirical results, but a discussion on the models' sensitivities to these parameters is needed. The sensitivity can be expressed as relative change of the 
model result divided by the relative change of the parameter $^{13}$, which gives the results shown in Table 4.

As seen in Table 4, the value of $\mathrm{k}$ has very little effect on the result. The values of $b$ and $z$ have larger impacts, since the model results are proportional to these.

\section{Behavior of the models}

As can be seen from Table 3, the largest profit contribution in the example calculation comes from the additional volume due to production increase. The electrical savings due to the higher energy efficiency at higher throughput appear to be minor in comparison. However, it is difficult to estimate what production increase may be made possible by a certain improvement of the quality control (i.e. to estimate the value of $z$ ), so this is also probably the model with the greatest uncertainty. Often, the production limitations are found in the paper machine, in which case an analysis of the relationship between the quality variations and the performance of the paper machine is needed. This would be an interesting but challenging topic for future work.

A new model for quantifying the economic value of better quality optimization has been developed, which is generic and should be applicable to a wide range of situations. The most important feature of this model is that it does not require any hard limits to be identified, but rather assumes a continuous cost function. Estimating one or both the slopes of the cost function is probably possible in many cases where hard limits may not exist, and in particular this would seem to be the case with freeness. One other important feature of this model is also that it works in cases with a symmetric cost function, that is, when it is not interesting to change the quality set point. This is because the model takes into account that all deviations from the optimal value have a negative economic effect.

\section{Conclusions}

While many studies have been performed to reduce the freeness variations, the economic value of this is less understood. Four areas of positive economic effects of reduced freeness variations have been modeled in this study.

The area that may have the greatest economic potential appears to be PM production rate increase; however this is also the model which is the most uncertain as it depends on what the limiting factors are and how strongly they are affected by quality variations. One economic benefit of production increase is higher energy efficiency in the refiners, but the value of the additional tonnes is considerably larger. Aside from the uncertain contribution from potential production increase, the most important contribution according to these estimates appears to be the increased availability of the paper machine due to fewer web breaks. Finally, there is also a smaller but still

\footnotetext{
${ }^{13}$ i.e. the sensitivity for $b$ is thus given by the unit-less expression: $\frac{d(\Delta V \ldots)}{d}, b$ and so on.

$\frac{d b}{d b} \cdot \frac{b}{\Delta V}$
}

Table 3. Summary of derived economic models.

$\begin{array}{llcc}\text { Mechanism } & \text { Model } & \begin{array}{c}\kappa \\ {[€ / \mathrm{t}]^{\star}}\end{array} & \begin{array}{c}\text { Savings } \\ \Delta V[€ / \text { year }]^{\star}\end{array} \\ \text { Reduction of web breaks } & \Delta V_{\text {break }}=\alpha P^{\text {old }} \cdot \frac{b f_{\text {break }}^{\text {old }} c \bar{t}_{\text {break }}}{a^{\text {old }} 24 h / \text { day }} & 2.8 & 170000\end{array}$

Production rate increase

$$
\begin{array}{llll}
\text { additional volume } & \Delta V_{p+c}=\alpha P^{\text {old }} \cdot z c & 7.5 & 450000 \\
\text { improved energy efficiency } & \Delta V_{p+e}=\alpha P^{\text {old }} \cdot z S E C^{\text {old }} v_{e} \beta(1-\gamma) & 0.6 & 37000
\end{array}
$$

Quality optimization/target shift $\Delta V_{Q \text { opt }}=\alpha P^{\text {old }} \cdot \sigma_{C S F}^{\text {old }}\left|\frac{d S E C}{d C S F}\right| v_{e}(1-\gamma) F(k) \quad 0.8 \quad 48000$

Using assumed example values

\begin{tabular}{|c|c|c|c|}
\hline \multirow[t]{2}{*}{ Model } & \multicolumn{3}{|c|}{ Sensitivity to parameter... } \\
\hline & $b$ & $k$ & $z$ \\
\hline$\Delta V_{\text {break }}$ & 1 & 0 & 0 \\
\hline$\Delta V_{p+c}$ & 0 & 0 & 1 \\
\hline$\Delta V_{p+e}$ & 0 & 0 & 1 \\
\hline$\Delta V_{\text {Qoot }}$ & 0 & 0.02 & 0 \\
\hline
\end{tabular}

Table 4. Model sensitivities.

notable contribution from the quality target shift and improved quality optimization.

It should also be mentioned that other positive effects beside these can be identified, though they are probably more difficult to estimate. As noted by Rönnbäck (2004), the economic potential of automatic control unfortunately appears to often be underestimated and overlooked.

\section{Acknowledgments}

The authors gratefully acknowledge the help and fruitful discussions from all the people at Holmen, Andritz, Chalmers University of Technology, Mid-Sweden University, Eurocon Optimation, Vattenfall and all others who have contributed to this work. We also want to thank the Knowledge Foundation (KK stiftelsen) and the Swedish Energy Agency for their financial support.

\section{Literature}

Berg, D. and Karlström, A. (2005): Energy Efficiency Modelling in ThermoMechanical Pulp Mills, International Mechanical Pulping Conference, Oslo, Norway, June 7-9, Papperindustriens Tekniske Forening, Oslo, Norway, pp. 248255.

Bohlin, G. and Hill, J. (1979): Automatic Quality Control of TMP Manufacture, Appita J. 32(5), 359

Deer, G., Carello, G., Fox, B. and Cloutier, D. (2007): Power Cost Reduction through Advanced Quality Control and Refiner Segment Change at Tembec Pine Falls, International Mechanical Pulping Conference, Minneapolis, Minnesota, May 7-9, TAPPI. Ferritsius, 0. and Ferritsius, R. (1997): Improved quality control and process design in production of mechanical pulp by the use of factor analysis, International Mechanical Pulping Conference, Stockholm, Sweden, June 9-13, SPCl, Stockholm, Sweden, pp. 111-125

Forsman, K. (2005): Reglerteknik för Processindustrin, Studentlitteratur AB, Lund, Sweden, pp. 227-243.

Hill, J. (1978): Värdet av automatiska styrsystem vid framställning av mekanisk massa, STFI report B 484, STFI, Stockholm, Sweden

Härkönen, E. and Tienvieri, T. (1995): The influence of production rate on refining in a specific refiner, International Mechanical Pulping Conference, Ottawa, Canada, June 12-15, Canadian Pulp and Paper Association, Montreal, Canada, pp. 177-182 
Joensuu, I., Karlsson, L. and Myllyneva, J. (2001): Fuzzy Quality Control of a TMP Plant, International Mechanical Pulping Conference, Helsinki, Finland, June 4-8, KCL, Helsinki, Finland, pp. 513-521.

Johansson, 0. (2001): Controlling High Consistency Refining Conditions through Refining Zone Temperature Optimization, 6th Pira International Refining Conference, Toronto, Canada, March 28-29, Leatherhead, UK: Pira international, Paper 12.

Johansson, 0., Jackson, M. and Wild, N. (2007): Three Steps to Improved TMP Operating Efficiency, International Mechanical Pulping Conference, Minneapolis, Minnesota, May 7-9, TAPPI.

Lidén, J. (2003): Quality Control of Single Stage Double Disc Chip Refining. Licentiate Thesis, Mid Sweden University, Sundsvall, Sweden.

Miller, J. and Miller, J.C. (2000): Statistics and Chemometrics for Analytical Chemistry, Pearson Education Limited, Harlow, England

Rönnbäck, S. (2004): Lönsamt att satsa på Reglerteknik, Nordisk Papper \& Massa, 40 (3-4), 40-41.

Sidhu, M.S., Lahouaoula, A., Kosunen, J. and Steele, T.H. (2005): Advances in Mechanical Pulping Control and Measurement, 91st Annual Meeting Pulp and Paper Technical Association of Canada, Montreal, Canada, February 8-20, PAPTAC, pp. 135-139. Sikter, D., Karlström, A., Engstrand, P. and Czmaidalka, J. (2007): Using the Refining Zone Temperature Profile for Quality Control, International Mechanical Pulping Conference, Minneapolis, Minnesota, May 7-9, TAPPI.
Strand, B.C., Falk, B., Mokvist, A. and Jackson, M. (1993): The Effect of Production Rate on Specific Energy Consumption in High Consistency Chip Refining, International Mechanical Pulping Conference, Oslo, Norway, June 1517, Technical Association of the Norwegian Pulp and Paper Industry, Oslo, Norway, pp. 143-151.

Strand, B.C. and Fralic, G. (2000): Economic Benefits from Advanced Quality Control of TMP Mills, Control Systems, Victoria, British Columbia, May 1-4, PAPTAC, Montreal, Canada, p. 11-15.

Strand, W.C., Quinn, H., Fralic, G., Moreira, A., Mozaffari, S. and Flynn, G. (2001): Millwide Advanced Quality Control for the Production of Newsprint, International Mechanical Pulping Conference, Helsinki, Finland, June 4-8, KCL, Helsinki, Finland, pp. 253-262.

Strand, B.C., Straight, J., Cole, D., Collins, T. and Norris, B. (2005): Factors affecting energy reduction in the production of newsprint from southern pine TMP, International Mechanical Pulping Conference, Oslo, Norway, June 7-9, 2005, Papperindustriens Tekniske Forening, Oslo, Norway, pp. 256-260.

Manuscript received September 28, 2007 Accepted January 16, 2008

\section{Appendix 1: Nomenclature}

Table 5. Latin symbols

\begin{tabular}{|c|c|c|c|}
\hline Variable & Unit & Description & Assumed value \\
\hline a & - & $\begin{array}{l}a \equiv P /\left(p_{P M} \cdot 8766 \mathrm{~h} / \text { year) }\right. \\
\text { (Availability of the paper machine) }\end{array}$ & $85 \%$ \\
\hline$b$ & - & Portion of web breaks that are due to pulp quality swings & 0.3 \\
\hline$c$ & $€ / t$ & $\begin{array}{l}\text { Contribution margin (income per tonne product minus variable } \\
\text { costs, e.g. raw material, electricity etc) }\end{array}$ & $150 € / t$ \\
\hline CSF & $\mathrm{ml}$ & Canadian Standard Freeness & \\
\hline$D$ & $€ /(\mathrm{t}[\mathrm{Q}])$ & The minimal absolute derivative of the approximated $v_{0}$ & \\
\hline$f_{\text {break }}$ & 1/day & Frequency of web breaks & 5 breaks/day \\
\hline$F(k)$ & - & $F(k) \equiv(k+1) / \sqrt{2 \pi} \cdot e^{-1 / 2 \Phi^{-1}(k /(k+1))^{2}}$ & \\
\hline k & - & The degree of asymmetry of the value function & 10 \\
\hline$k_{p+}$ & - & $\begin{array}{l}k_{p+} \equiv p^{\text {new }} / p^{\text {old }} \\
\text { The assumed or estimated factor of production } \\
\text { increase with improved control }\end{array}$ & 1.015 \\
\hline$N\left(x, \bar{x}, \sigma_{x}\right)$ & {$[\mathrm{X}]^{-1}$} & $\begin{array}{l}\text { The normal distribution function, i.e. } \\
\qquad N\left(x, \bar{x}, \sigma_{x}\right)=\left(2 \pi \sigma_{x}^{2}\right)^{-1 / 2} e^{-1 / 2(x-\bar{x})^{2} / \sigma_{x}^{2}}\end{array}$ & \\
\hline$p$ & $\mathrm{t} / \mathrm{h}$ & Production rate while running & \\
\hline$P$ & t/year & $\begin{array}{l}\text { Total yearly produced volume } \\
\text { (unlike } p \text {, downtime is included in this term) }\end{array}$ & 200000 t/year \\
\hline$Q$ & {$[Q]$} & The quality parameter of interest. & CSF \\
\hline$S$ & $\mathrm{t} / \mathrm{t}$ & $\begin{array}{l}\text { Specific steam consumption in paper machine, } \\
\text { i.e. tonnes of steam per tonne of paper. }\end{array}$ & \\
\hline SEC & $\mathrm{MWh} / \mathrm{t}$ & Specific energy consumption in refining & $2 \mathrm{MWh} / \mathrm{t}$ \\
\hline $\bar{t}_{\text {break }}$ & h & Average time of a web break & $0.25 \mathrm{~h}$ \\
\hline V & $€ / t$ & Cost per tonne (variable costs) & \\
\hline$V_{e}$ & $€ / M W h$ & Cost of electrical energy & $40 € / M W h$ \\
\hline$V_{s}$ & $€ / t$ & The mill's average perceived value of 1 tonne of TMP steam* & \\
\hline$v_{Q}(Q)$ & $€ / t$ & Variable costs as a function of the quality $Q$ & \\
\hline V & $€ /$ year & Profit per year & \\
\hline \multirow[t]{2}{*}{$z$} & - & $k_{p+}-1 \approx z \cdot \alpha$ & \\
\hline & & $\begin{array}{l}\text { (The relationship between control improvement } \\
\text { and enabled production increase) }\end{array}$ & 0.05 \\
\hline
\end{tabular}


Table 6. Greek symbols

\begin{tabular}{|c|c|c|c|}
\hline Variable & Unit & Description & Assumed value \\
\hline \multirow[t]{2}{*}{$\alpha$} & - & $\alpha \equiv 1-\sigma_{Q}^{\text {new }} / \sigma_{Q}^{\text {old }}$ & \\
\hline & & $\begin{array}{l}\text { (Relative improvement } \\
\text { of quality control) }\end{array}$ & 0.3 \\
\hline$\alpha_{\text {rec }}$ & t/MWh & $\begin{array}{l}\text { Recovered (cleaned) steam } \\
\text { per invested energy* in the } \\
\text { refining stages }\end{array}$ & \\
\hline$\beta$ & - & $\beta \equiv-\frac{d S E C}{d p_{\text {ref }}} \frac{p_{\text {ref }}^{\text {old }}}{S E C^{\text {old }}} \quad$ (at constant quality) & 0.3 \\
\hline \multirow[t]{2}{*}{$\gamma$} & - & $\gamma \equiv v_{s} \alpha_{r e c} / v_{e}$ & 0.5 \\
\hline & & $\begin{array}{l}\text { (The perceived value of cleaned, } \\
\text { recovered refiner steam divided } \\
\text { by the energy cost of producing it*) }\end{array}$ & \\
\hline$\kappa$ & $€ / t$ & $\kappa \equiv \Delta V /\left(\alpha P^{o l d}\right)$ & \\
\hline$\sigma_{C S F}$ & $\mathrm{ml}$ & Standard deviation in CSF & $\begin{array}{c}15 \mathrm{ml} \text { (old) } \\
10.5 \mathrm{ml} \text { (new) }\end{array}$ \\
\hline$\sigma_{Q}$ & {$[\mathrm{Q}]$} & Standard deviation in $Q$ & \\
\hline \multirow[t]{2}{*}{$\phi(x)$} & - & $\begin{array}{l}\text { The standard cumulative normal } \\
\text { distribution, i.e. }\end{array}$ & \\
\hline & & $\Phi(x) \equiv \int N(z, 0,1) d z$ & \\
\hline
\end{tabular}

Table 7. Superscripts

\begin{tabular}{ll}
\hline Superscript & Interpretation \\
\hline$x^{\text {old }}$ & The value of $x$ before control improvement \\
$x^{\text {new }}$ & The value of $x$ after control improvement \\
$\bar{x}$ & The average value of $x$ \\
\hline
\end{tabular}

Table 8. Prefixes

\begin{tabular}{ll}
\hline Prefix & Interpretation \\
\hline$\Delta x$ & The change in $x$, i.e. $x^{\text {new }}-x^{\text {old }}$ \\
\hline
\end{tabular}

Table 9. Subscripts

\begin{tabular}{ll}
\hline Subscript & Interpretation \\
\hline break & Related to web breaks \\
$C$ & Related to the selling value of paper \\
CSF+ & Related to CSF target shift \\
$e$ & Related to electrical energy \\
$E$ & Related to energy \\
$p+$ & Related to production rate increase \\
$P M$ & Related to the paper machine \\
Qopt & Related to quality optimization \\
$r e f$ & Related to an individual refiner \\
$S$ & Related to steam \\
\hline
\end{tabular}

* on the margin, i.e. fixed costs, no-load losses etc not included 